\title{
Adult-Onset Leukoencephalopathy with Axonal Spheroids and Pigmented Glia: An MRI Study of 16 French Cases
}



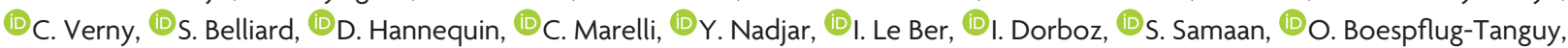 \\ (1)S. Lumbroso, and (1DP. Labauge
}

\begin{abstract}
SUMMARY: Adult-onset leukoencephalopathy with axonal spheroids and pigmented glia is an autosomal dominant leukoencephalopathy related to CSFR gene mutations. A growing number of clinicoradiologic phenotypes have been described. In this study, we analyzed brain imaging findings in 16 patients with adult-onset leukoencephalopathy with axonal spheroids and pigmented glia to refine radiologic diagnostic clues. T2/FLAIR white matter hyperintensities were present in all patients with frontal or frontoparietal predilection, with asymmetric distribution in more than one-third. Brain atrophy and callosal involvement were almost constant, and corticospinal tract involvement was frequent. Moreover, deep white matter hyperintense dots on DWI and deep punctate calcifications on CT were often found. Conversely, deep gray matter nuclei, external capsules, and brain stem were rarely involved. Our series emphasized the great variability of MR imaging findings seen in adult-onset leukoencephalopathy with axonal spheroids and pigmented glia. A complete imaging screening including $\mathrm{DWI}, \mathrm{T}^{*}$, and $\mathrm{CT}$ is mandatory to accurately assess patients with suspected inherited adult-onset leukoencephalopathy.
\end{abstract}

ABBREVIATIONS: ALSP = adult-onset leukoencephalopathy with axonal spheroids and pigmented glia; $F T L D=$ frontotemporal lobar degeneration; $\mathrm{WMH}=$ white matter hyperintensities

A dult-onset leukoencephalopathy with axonal spheroids and pigmented glia (ALSP) is an autosomal dominant leukoencephalopathy related to heterozygous mutations in the colony stimulating factor 1 receptor (CSF1R) gene. ${ }^{1}$ To date, $>50$ CSF1R mutations and multiple clinicoradiologic phenotypes have been described. ${ }^{2}$ ALSP is increasingly recognized as one of the most common causes of adult-onset inherited leukoencephalopathy. ${ }^{3}$

Received January 28, 2018; accepted after revision May 1.

From the Department of Neurology (P.C., X.A., C.C.-D., C.M., P.L.), Montpellier University Hospital, Montpellier, France; Departments of Biochemistry and Molecular Biology (K.M., S.L.) and Neurology (G.C.), Nîmes University Hospital, Nîmes, France; Department of Neurology (E.E.), Côte Basque Hospital, Bayonne, France; Department of Neurology (F.E.-B., C.V.), Angers University Hospital, Angers, France; Department of Neurology (S.B.), Rennes University Hospital, Rennes, France; Department of Neurology (D.H.), Rouen University Hospital, Rouen, France; Departments of Neurology (Y.N., I.L.B.) and Genetics (F.M.), Assistance Publique-Hôpitaux de Paris, Pitié-Salpêtrière University Hospital, Paris, France; and Department of Neuropediatrics and Metabolic Disorders (I.D., S.S., O.B.-T.), Assistance Publique-Hôpitaux de Paris, Robert Debré University Hospital, Paris, France.

Serge Lumbroso and Pierre Labauge contributed equally as last authors.

The research leading to these results has received funding from the program "Investissements d'avenir" ANR-10-IAIHU-06. This work was funded by the PHRC (Programme Hospitalier de Recherche Clinique) FTLD exome (promotion Assistance Publique-Hôpitaux de Paris to I.L.B.)

Please address correspondence to Xavier Ayrignac, MD, Department of Neurology, Montpellier University Hospital, 80 Rue Augustin Fliche, 34295 Montpellier, Cedex 05, France; e-mail: xavier.ayrignac@yahoo.fr

- Indicates open access to non-subscribers at www.ajnr.org

http://dx.doi.org/10.3174/ajnr.A5744
ALSP diagnosis is still challenging because of the multiple presentations that can mimic frontotemporal lobar degeneration (FTLD), atypical parkinsonism, CADASIL, or primary-progressive MS. ${ }^{1,3-5}$ Indeed, initial descriptions of ALSP included lateonset psychiatric and cognitive impairment with MR imaging frontal white matter changes and atrophy. Following the genetic characterization of the disease, more distinctive imaging findings have been identified, including deep punctate calcifications, persistent DWI small diffusion-restricted lesions, and corpus callosum thinning. ${ }^{6-8}$ In this study, we analyzed imaging findings in 16 patients with genetically confirmed ALSP to refine imaging characteristics and improve its diagnostic rate.

\section{Case Series}

Sixteen patients with ALSP ( 9 women, 7 men) from 10 unrelated families were identified in 7 neurologic centers. Five patients had a longitudinal MR imaging evaluation. T1WI, T2WI, and FLAIR were available for all patients. T1WI with gadolinium contrast medium $(n=6)$, DWI $(n=8)$, and T2* $(n=8)$ were available for some patients. Six patients had a brain CT. Seven patients have been previously described. $3,4,9,10$

\section{Clinical and Genetic Findings}

Thirteen patients had a positive family history of ALSP (Table 1). The mean age of onset was 45.8 years (range, 28-60 years). Initial 
Table 1: Clinical and genetic findings

\begin{tabular}{|c|c|c|c|c|c|c|c|}
\hline Case & Sex & $\begin{array}{l}\text { Age at Onset } \\
(y r)\end{array}$ & Family History & Initial Symptoms & First Suspected Diagnosis & CSFIR Mutation & MRI Delay (yr) \\
\hline 1 & M & 57 & Yes & Cognitive/psychiatric & FTLD (genetic form) & c.2330G >A(p.Arg777Gln) & 1 \\
\hline 2 & M & 44 & Yes & Cognitive & FTLD (genetic form) & c.2330G > A(p.Arg777Gln) & 4 \\
\hline 3 & $\mathrm{~F}$ & 42 & Yes & Parkinsonism & Corticobasal degeneration & c.2566T>C(p.Tyr856His) & 3 \\
\hline 4 & M & 28 & Yes & Gait & CNS lesions related to celiac disease & c.2381T >C(p.lle794Thr) & 4 \\
\hline 5 & M & 57 & Yes & Speech & Undetermined leukoencephalopathy & c.2381T >C(p.Ile794Thr) & 5 \\
\hline 6 & $\mathrm{~F}$ & 28 & No & Gait/apraxia & Undetermined leukoencephalopathy & c.2381T>C(p.Ile794Thr) & 0.5 \\
\hline 7 & $\mathrm{~F}$ & 31 & No & Motor & PPMS & c.2342C>T(p.Ala781Val) & 1.5 \\
\hline 8 & M & 60 & Yes & Cognitive/apraxia & Corticobasal degeneration & c.2525G $>$ T(p.Gly842Val) ${ }^{a}$ & 1 \\
\hline 9 & $\mathrm{~F}$ & 47 & Yes & Parkinsonism & $\begin{array}{l}\text { Vascular leukoencephalopathy } \\
\text { (inherited) }\end{array}$ & c. $2522 \mathrm{~A}>\mathrm{G}\left(\right.$ p.Tyr841Cys) ${ }^{\mathrm{a}}$ & 1 \\
\hline 10 & $\mathrm{~F}$ & 60 & Yes & Cognitive/parkinsonism & $\begin{array}{l}\text { Vascular leukoencephalopathy } \\
\text { (inherited) }\end{array}$ & c. $2522 \mathrm{~A}>\mathrm{G}(\mathrm{p} . \text { Tyr841Cys })^{\mathrm{a}}$ & 1 \\
\hline 11 & M & 36 & Yes & Cognitive & LCC & $c .2534 \mathrm{~T}>C(p . \text { Leu845Pro })^{\mathrm{a}}$ & 2 \\
\hline 12 & $\mathrm{~F}$ & 55 & Yes & Psychiatric/speech & LCC & c.2534T $>C(p . L e u 845 \text { Pro })^{a}$ & 2 \\
\hline 13 & $\mathrm{~F}$ & - & Yes & Asymptomatic & NA & c. $2498 C>A(p . T h r 833 \text { Lys })^{a}$ & $49^{b}$ \\
\hline 14 & $\mathrm{~F}$ & 57 & Yes & Cognitive & FTLD (genetic form) & c.2498C $>$ A(p.Thr833Lys $)^{a}$ & 1 \\
\hline 15 & $\mathrm{~F}$ & 33 & Yes & Gait & NA & c.2498C $>$ A(p.Thr833Lys $)^{a}$ & 0.5 \\
\hline 16 & M & 52 & No & Cognitive/psychiatric & $\begin{array}{l}\text { Vascular leukoencephalopathy } \\
\text { (inherited) }\end{array}$ & c.2308G > C(p.Ala770Pro) & 2 \\
\hline
\end{tabular}

Note:-NA indicates not applicable (diagnosis already known in family member); PPMS, primary-progressive MS; LCC, leukoencephalopathy with calcifications and cysts.

${ }^{\text {a }}$ Mutation not previously described.

b Patient asymptomatic at the time of MRI. Each family is separated by dashed lines.

symptoms included cognitive impairment (44\%), psychiatric symptoms (19\%), parkinsonism (19\%), gait ataxia (19\%), apraxia (13\%), speech problems (13\%), and motor dysfunction (6\%). Nine different pathogenic CSF1R mutations were identified, including 5 previously reported mutations. All mutations involved the CSF1R tyrosine kinase domain with no overt correlation between mutations and the patient's phenotypes or MR imaging findings.

\section{Imaging Findings}

White Matter Hyperintensities. The mean delay between symptom onset and MR imaging was 2.0 years (range, $0.5-5$ years). Bilateral, predominantly frontal and parietal T2/FLAIR white matter hyperintensities (WMH) associated with T1 hypointensities were present in all patients, even if they were subtle in some patients (Fig $1 A$ and Table 2). Temporal and occipital abnormalities were observed in, respectively, $69 \%$ and $50 \%$ of the cases. $\mathrm{WMH}$ were confluent in 63\% (Fig 1B) and patchy in 37\% (Fig $1 C$ ), and a clear asymmetry was seen $37 \%$ of the patients (Fig 1D).

Pyramidal tract hyperintensities were noted in $63 \%$ of the patients (Fig $1 A,-E$ ), with an involvement of the internal capsules in 10 and of the brain stem in 3. Three patients had spinal cord MR imaging; findings were always normal. Corpus callosum abnormalities were almost always present with hyperintensities in $81 \%$ (Fig $1 F$ ) and atrophy in $88 \%$ of cases (Fig $1 G$ ). Deep gray matter nuclei and external capsules were involved in, respectively, 13\% and $44 \%$ of patients. Posterior fossa hyperintensities were seen in $37 \%$ of the patients: Half of these patients had pontine vascularlike lesions (Fig 1H). The cerebellum was always spared. Enlarged perivascular spaces were seen in $25 \%$ of patients (Fig $1 I$ ).

Atrophy. Brain atrophy was almost constant (94\%), and 4 patients had marked atrophy (Fig $1 J$ ). It was usually more pronounced in patients with diffuse $\mathrm{WMH}$ and predominated in the frontal (40\%) or frontoparietal (53\%) areas.

DWI and Calcifications. Multiple small deep white matter DWI diffusion-restricted lesions were observed in 6 of 8 patients, including 4 with a restriction of the apparent diffusion coefficient
(Fig 2). On CT, calcifications were found in 4 of 6 patients (Fig 3), but they were not identified with $\mathrm{T} 2 *$ imaging.

Other Features. None of the 6 patients with contrast MR imaging showed gadolinium enhancement. Ventricular abnormalities, including cavum septum pellucidum and/or cavum vergae (Fig $1 A$, $-B$ ), were seen in $50 \%$ of the patients. Five patients (cases $7,8,11$, 14 , and 15) had an MR imaging follow-up after a mean of 15.3 months (range, 5-32 months): Supratentorial WMH worsened in all patients (Fig $1 K,-L$ ), usually associated with marked brain volume loss.

\section{DISCUSSION}

Our series emphasizes the great variability of MR imaging findings seen in ALSP. Likewise, only 44\% of our patients corresponded to the initial description (before the era of genetic screening) of patients with ALSP with cognitive impairment and psychiatric symptoms associated with marked frontoparietal hyperintensities and atrophy. ${ }^{11}$ FTLD is one of the main differential diagnoses of ALSP, though WMH are rarely seen in FTLD, with the exception of patients with GRN mutations. ${ }^{12}$ Recent data suggest that patients can also be misdiagnosed as having inflammatory disorders or vascular leukoencephalopathies. ${ }^{5,13,14}$ In our series, inflammatory diseases (primary-progressive MS and celiac disease-related CNS lesions) were initially suspected in 2 patients, and a vascular leukoencephalopathy, in 3. In patients who had MR imaging with patchy and sometimes periventricular lesions like those potentially seen in MS, in the absence of CSF oligoclonal bands and in patients with a rapid worsening of disability, ALSP should be suspected. In these cases, absence of typical periventricular Dawson finger lesions, marked corpus callosum atrophy, and persistent DWI hyperintensities and CT microcalcifications should be sought and, if present, should warrant CSF1R gene sequencing.

$\mathrm{WMH}$, as previously described, always involved frontal and parietal white matter, but temporal and occipital involvement (though usually mild) was also common, respectively, in 69\% and $50 \%$ of the cases compared with $<20 \%$ in previous studies. ${ }^{7,8}$ Moreover, the "patchy" pattern frequently observed in ALSP is 


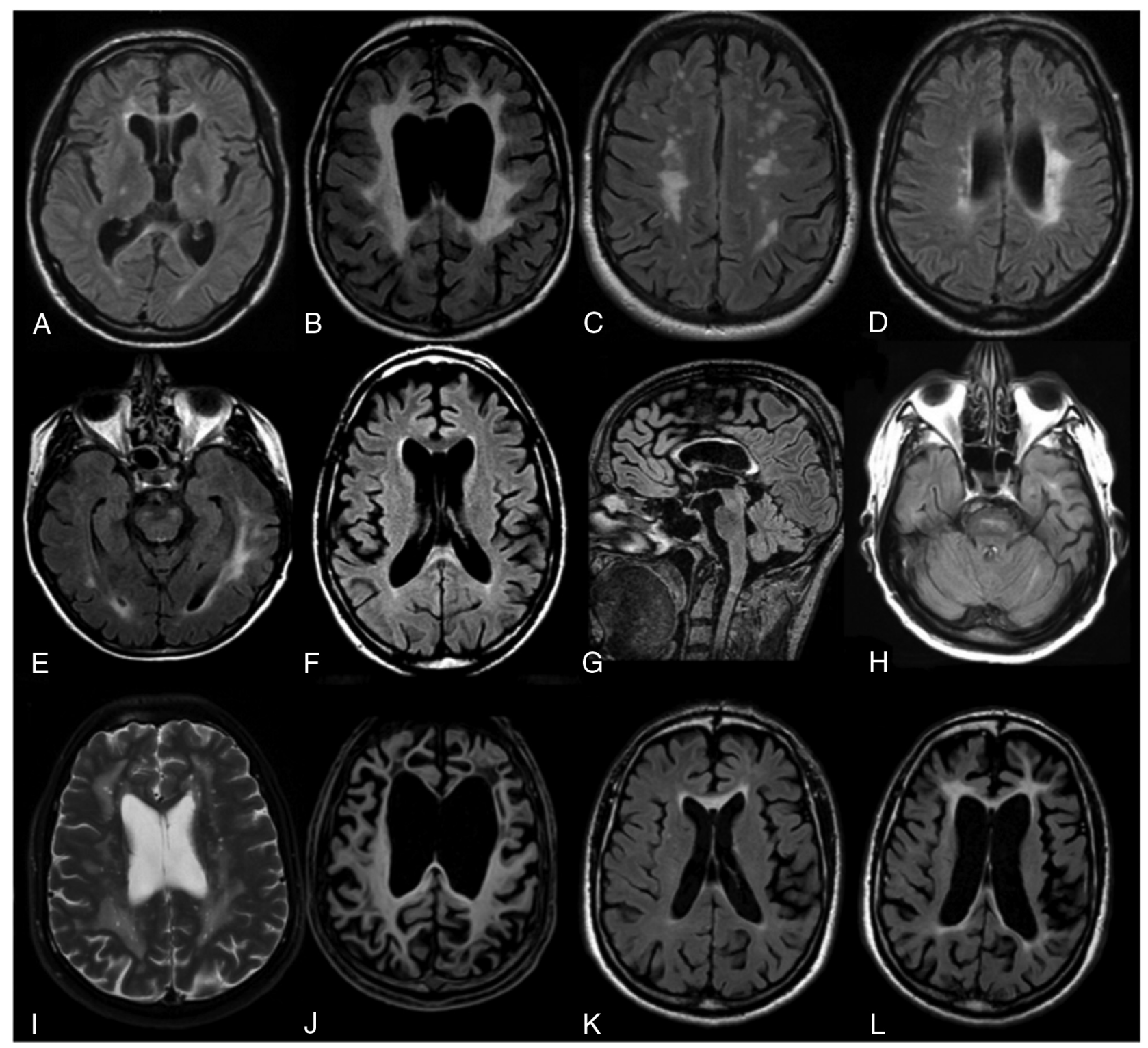

FIG 1. Characteristic MR imaging abnormalities in patients with ALSP on FLAIR $(A-H, K, L)$, T2WI (I), and TIWI (I) images. MR imaging usually discloses subtle $(A)$ or marked $(B)$ white mater hyperintensities with frontal predilection $(B)$. WMH can be confluent $(B)$ or patchy $(C)$ and are usually asymmetric $(D)$. Corticospinal tract involvement $(A$ and $E$ ) and corpus callosum involvement $(F$ and $G)$ are frequent. At the posterior fossa level, WMH can be of a vascular-like type $(H)$. Some patients can present with enlarged perivascular spaces on T2WI (I). TTWI frequently reveals atrophy, usually marked, with frontal predominance ()). During a 32-month follow-up (case 8), a clear increase of WMH and atrophy is seen ( $K$ and $L)$. A cavum septum pellucidum is frequently observed $(A$ and $B)$.

rarely seen in other adult-onset leukoencephalopathies and usually suggests an inflammatory or vascular (acquired or inherited) etiology. ${ }^{5}$ Finally, asymmetric hyperintensities are rarely reported in inherited white matter disorders. Besides ALSP, they have been mainly described in AARS2-related leukoencephalopathy, retinal vasculopathy with cerebral leukoencephalopathy, Alexander disease, and leukoencephalopathy with calcifications and cysts. ${ }^{7,15,16}$ Our data confirmed that asymmetric lesions are present in ALSP (37\%), and a recent series reported an even higher occurrence of asymmetric WMH (90\%).?

Deep small white matter DWI diffusion-restricted lesions, often associated with a restriction on an ADC map, were found in $6 / 8$ patients. They are characteristic of the disease because they have only been reported in ALSP (two-thirds of the patients) and in AARS2-related leukoencephalopathy (100\%)..$^{2,7,14,17}$ As previously described, our single patient with serial MR imaging and DWI sequences had persistent $b=1000$ hyperintensities. ${ }^{7,17}$ Other series have suggested that small calcifications with a stepping stone distribution were characteristic of the disease, but their frequency has not been reported to date. ${ }^{6,18}$ Here, we found calcifications in $4 / 6$ patients who had undergone CT, stressing that they are likely frequent in ALSP. Of note, none of our patients with calcifications on CT had identifiable $\mathrm{T} 2 *$ hypointensities.

Atrophy (88\%) and/or hyperintensities (81\%) were frequently seen in the corpus callosum. In some patients, the corpus callosum was markedly involved, despite very subtle white matter abnormalities. ${ }^{19}$ Conversely, deep gray matter nuclei (13\%) and the external capsule (44\%) were rarely involved. Accordingly, such 
Table 2: Neuroimaging findings

\begin{tabular}{|c|c|c|c|c|c|}
\hline Imaging Findings & No. & $\%$ & Imaging Findings & No. & $\%$ \\
\hline White matter abnormalities & $16 / 16$ & 100 & $\begin{array}{l}\text { Atrophy } \\
\text { Atrophy predominance }\end{array}$ & $15 / 16$ & 94 \\
\hline Symmetry & & & Frontal & $6 / 15$ & 40 \\
\hline Symmetric & $10 / 16$ & 63 & Frontoparietal & $8 / 15$ & 53 \\
\hline Asymmetric & $6 / 16$ & 37 & Parietal & $1 / 15$ & 7 \\
\hline Confluence of lesions & & & Corpus callosum involvement & & \\
\hline Confluent & $10 / 16$ & 63 & Hyperintensities & $13 / 16$ & 81 \\
\hline Patchy & $6 / 16$ & 37 & Atrophy & $14 / 16$ & 88 \\
\hline $\begin{array}{l}\text { White matter abnormalities } \\
\text { predominance }\end{array}$ & & & $\begin{array}{l}\text { Corticospinal tract } \\
\text { Deep gray matter nuclei }\end{array}$ & $\begin{array}{r}10 / 16 \\
2 / 16\end{array}$ & $\begin{array}{r}63 \\
13\end{array}$ \\
\hline Frontal & $13 / 16$ & 81 & External capsule & $7 / 16$ & 44 \\
\hline Frontoparietal & $3 / 16$ & 19 & $\begin{array}{l}\text { Posterior fossa } \\
\text { Enlarged perivascular spaces }\end{array}$ & $\begin{array}{l}6 / 16 \\
4 / 16\end{array}$ & $\begin{array}{l}37 \\
25\end{array}$ \\
\hline Lobar distribution & & & Diffusion-weighted imaging & & \\
\hline Frontal & $16 / 16$ & 100 & Hyperintensities & $6 / 8$ & 75 \\
\hline Parietal & $16 / 16$ & 100 & Restricted ADC & $4 / 6$ & 67 \\
\hline Temporal & $11 / 16$ & 69 & Calcifications & & \\
\hline Occipital & $8 / 16$ & 50 & $\mathrm{~T}^{*}$ & $0 / 8$ & 0 \\
\hline & & & CT & $4 / 6$ & 67 \\
\hline U-fiber involvement & $8 / 16$ & 50 & Gadolinium enhancement & $0 / 6$ & 0 \\
\hline White matter rarefaction & $0 / 16$ & 0 & Cavum septum pellucidum & $8 / 16$ & 50 \\
\hline
\end{tabular}

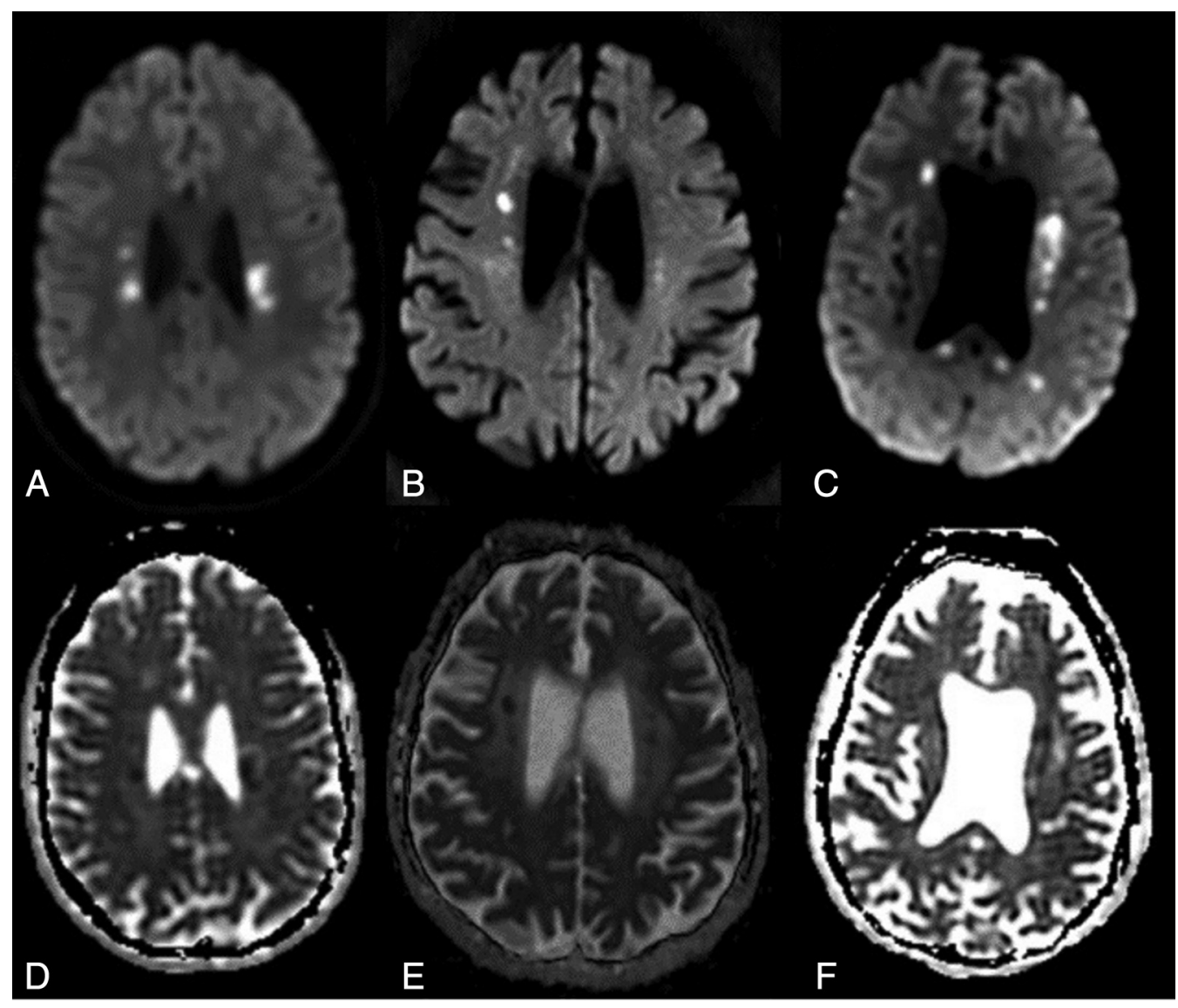

FIG 2. Typical DWI in ALSP. Persistent deep white matter diffusion-restricted lesions $(A-C)$ with corresponding low $A D C$ values $(D-F)$ are found.

features in patients with patchy WMH, along with the absence of $\mathrm{T} 2 *$ microbleeds, help distinguish acquired or inherited vascular leukoencephalopathy from ALSP. ${ }^{7,8,20}$ Similarly, of the 6 patients with pontine hyperintensities, only 3 had lesions suggestive of a vascular origin, whereas the other patients had corticospinal tract hyperintensities.
Altogether, this series emphasized the striking variability of MR imaging patterns in ALSP, suggesting that to date, this condition is probably markedly underestimated. Moreover, in patients suspected of having inherited leukoencephalopathy, we confirmed that an asymmetric distribution of WMH, persistent DWI hyperintense white matter diffusion-restricted lesions, and 


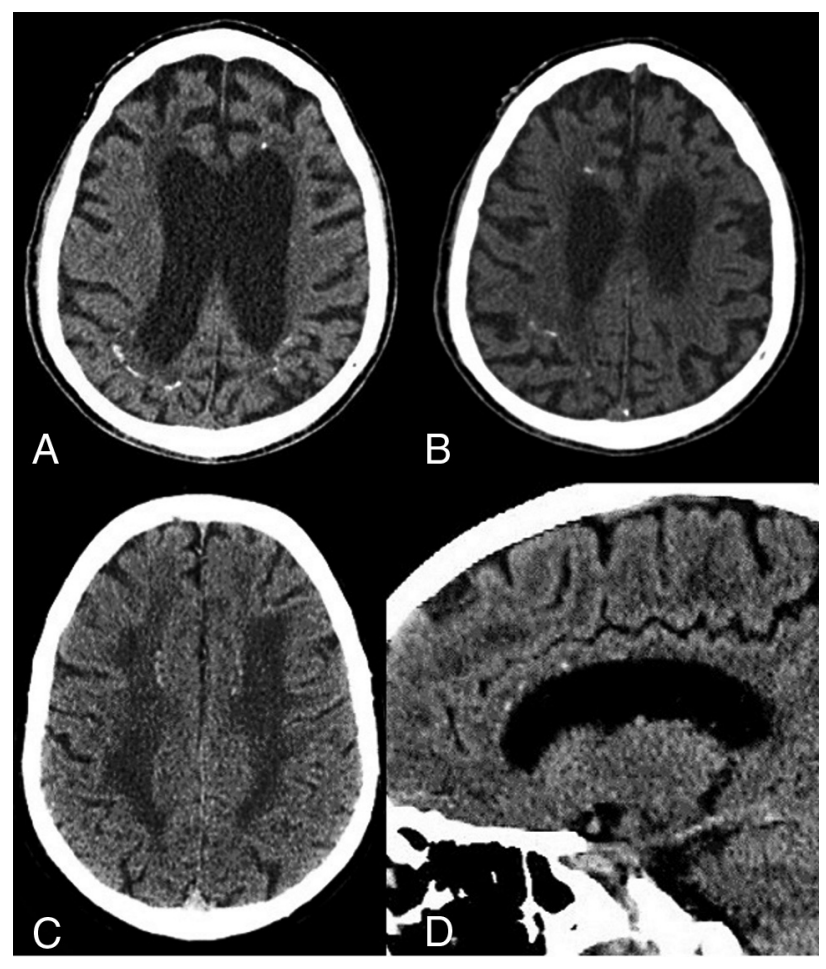

FIG 3. Small calcifications in ALSP. CT images reveal punctate calcifications located in the subcortical parietal WM and the periventricular frontal WM $(A-C)$. Sagittal reconstruction shows the typical stepping stone distribution $(D)$.

punctate calcifications are highly suggestive of ALSP. Likewise, a complete imaging screening, including DWI, T2* ${ }^{*}$ and CT, is key to accurately assess patients suspected of having inherited adultonset leukoencephalopathy. The early detection of CSF1R-related leukoencephalopathy is even more critical because hematopoietic stem cell transplantation may be a promising therapy for patients and their at-risk relatives. ${ }^{21}$

Disclosures: Fanny Mochel—UNRELATED: Consultancy: Ultragenyx Pharmaceuticals, Comments: expert at investigator meetings for Phase 3 study; Expert Testimony: Haute Autorité de Santé, Comments: expert opinion on an Orphan drug for a rare neurometabolic disease; Grants/Grants Pending: Programme Hospitalier de Recherche Clinique, Direction Générale de l'Offre de Soins, Ultragenyx, Comments: clinical trial: NCT02336633, clinical trial: NCT02639871, clinical trial: NCT02453061*; Patents (Planned, Pending or Issued): EP1929995 Al. Serge Belliard-UNRELATED: Board Membership: Lilly, Comments: board for development of antiamyloid treatments. Cecilia Marelli-UNRELATED: Payment for Development of Educational Presentations: Actelion Pharmaceuticals; Travel/Accommodations/Meeting Expenses Unrelated to Activities Listed: Nutricia Metabolics. Yann Nadjar-UNRELATED: Grants/Grants Pending: Leadiant and Retrophin, Comments: financial support for clinical studies about cerebrotendinous xanthomatosis from 2 pharmaceutical companies*; Payment for Lectures Including Service on Speakers Bureaus: lectures about Fabry disease (from Amicus Therapeutics) and dementias from inherited metabolic disease (from Orphan Europe); Payment for Manuscript Preparation: from Orphan Europe, concerning a manuscript about MTHFR deficiency*; Patents (Planned, Pending or Issued): from Orphan Europe, to develop a Web site concerning neurometabolic diseases. *Money paid to the institution.

\section{REFERENCES}

1. Rademakers R, Baker M, Nicholson AM, et al. Mutations in the colony stimulating factor 1 receptor (CSF1R) gene cause hereditary diffuse leukoencephalopathy with spheroids. Nat Genet 2011;44: 200-05 CrossRef Medline

2. Konno T, Yoshida K, Mizuno T, et al. Clinical and genetic charac- terization of adult-onset leukoencephalopathy with axonal spheroids and pigmented glia associated with CSF1R mutation. Eur J Neurol 2017;24:37-45 CrossRef Medline

3. Guerreiro R, Kara E, Le Ber I, et al. Genetic analysis of inherited leukodystrophies: genotype-phenotype correlations in the CSF1R gene. JAMA Neurol 2013;70:875-82 CrossRef Medline

4. Prieto-Morin C, Ayrignac X, Ellie E, et al. CSF1R-related leukoencephalopathy mimicking primary progressive multiple sclerosis. J Neurol 2016;263:1864-65 CrossRef Medline

5. Lynch DS, Jaunmuktane Z, Sheerin UM, et al. Hereditary leukoencephalopathy with axonal spheroids: a spectrum of phenotypes from CNS vasculitis to parkinsonism in an adult onset leukodystrophy series. J Neurol Neurosurg Psychiatry 2016;87:512-19 CrossRef Medline

6. Konno T, Broderick DF, Mezaki N, et al. Diagnostic value of brain calcifications in adult-onset leukoencephalopathy with axonal spheroids and pigmented glia. AJNR Am J Neuroradiol 2017;38: 77-83 CrossRef Medline

7. Lakshmanan R, Adams ME, Lynch DS, et al. Redefining the phenotype of ALSP and AARS2 mutation-related leukodystrophy. Neurol Genet 2017;3:e135 CrossRef Medline

8. Sundal C, Van Gerpen JA, Nicholson AM, et al. MRI characteristics and scoring in HDLS due to CSF1R gene mutations. Neurology 2012; 79:566-74 CrossRef Medline

9. Letournel F, Etcharry-Bouyx F, Verny C, et al. Two clinicopathological cases of a dominantly inherited, adult onset orthochromatic leucodystrophy. J Neurol Neurosurg Psychiatry 2003;74: 671-73 CrossRef Medline

10. Labauge P, Berger E, Magnin E, et al. A new form of leukoencephalopathy with calcifications and cysts with nonrecessive inheritance and absence of gadolinium enhancement. Eur Neurol 2012;67: 151-53 CrossRef Medline

11. van der Knaap MS, Naidu S, Kleinschmidt-Demasters BK, et al. Autosomal dominant diffuse leukoencephalopathy with neuroaxonal spheroids. Neurology 2000;54:463-68 CrossRef Medline

12. Caroppo P, Le Ber I, Camuzat A, et al. Extensive white matter involvement in patients with frontotemporal lobar degeneration: think progranulin. JAMA Neurol 2014;71:1562-66 CrossRef Medline

13. Sundal C, Baker M, Karrenbauer V, et al. Hereditary diffuse leukoencephalopathy with spheroids with phenotype of primary progressive multiple sclerosis. Eur J Neurol 2015;22:328-33 CrossRef Medline

14. Battisti C, Di Donato I, Bianchi S, et al. Hereditary diffuse leukoencephalopathy with axonal spheroids: three patients with stroke-like presentation carrying new mutations in the CSF1R gene. J Neurol 2014;261:768-72 CrossRef Medline

15. Stam AH, Kothari $\mathrm{PH}$, Shaikh A, et al. Retinal vasculopathy with cerebral leukoencephalopathy and systemic manifestations. Brain 2016;139:2909-22 CrossRef Medline

16. Wang $\mathrm{M}$, Zhang $\mathrm{M}, \mathrm{Wu} \mathrm{L}$, et al. Leukoencephalopathy with cerebral calcification and cysts: cases report and literature review. J Neurol Sci 2016;370:173-79 CrossRef Medline

17. Terasawa $Y$, Osaki $Y$, Kawarai $T$, et al. Increasing and persistent DWI changes in a patient with hereditary diffuse leukoencephalopathy with spheroids. J Neurol Sci 2013;335:213-15 CrossRef Medline

18. Ayrignac X, Nicolas G, Carra-Dallière C, et al. Brain calcifications in adult-onset genetic leukoencephalopathies: a review. JAMA Neurol 2017;74:1000-08 CrossRef Medline

19. Kondo Y, Kinoshita M, Fukushima K, et al. Early involvement of the corpus callosum in a patient with hereditary diffuse leukoencephalopathy with spheroids carrying the de novo K793T mutation of CSF1R. Intern Med 2013;52:503-06 CrossRef Medline

20. Ayrignac X, Carra-Dalliere C, Menjot de Champfleur N, et al. Adultonset genetic leukoencephalopathies: a MRI pattern-based approach in a comprehensive study of 154 patients. Brain 2015;138 (Pt 2):284-92 CrossRef Medline

21. Eichler FS, Li J, Guo Y, et al. CSF1R mosaicism in a family with hereditary diffuse leukoencephalopathy with spheroids. Brain 2016;139:1666-72 CrossRef Medline 